\title{
Lithography-Based Ceramics Manufacturing Technologies
}

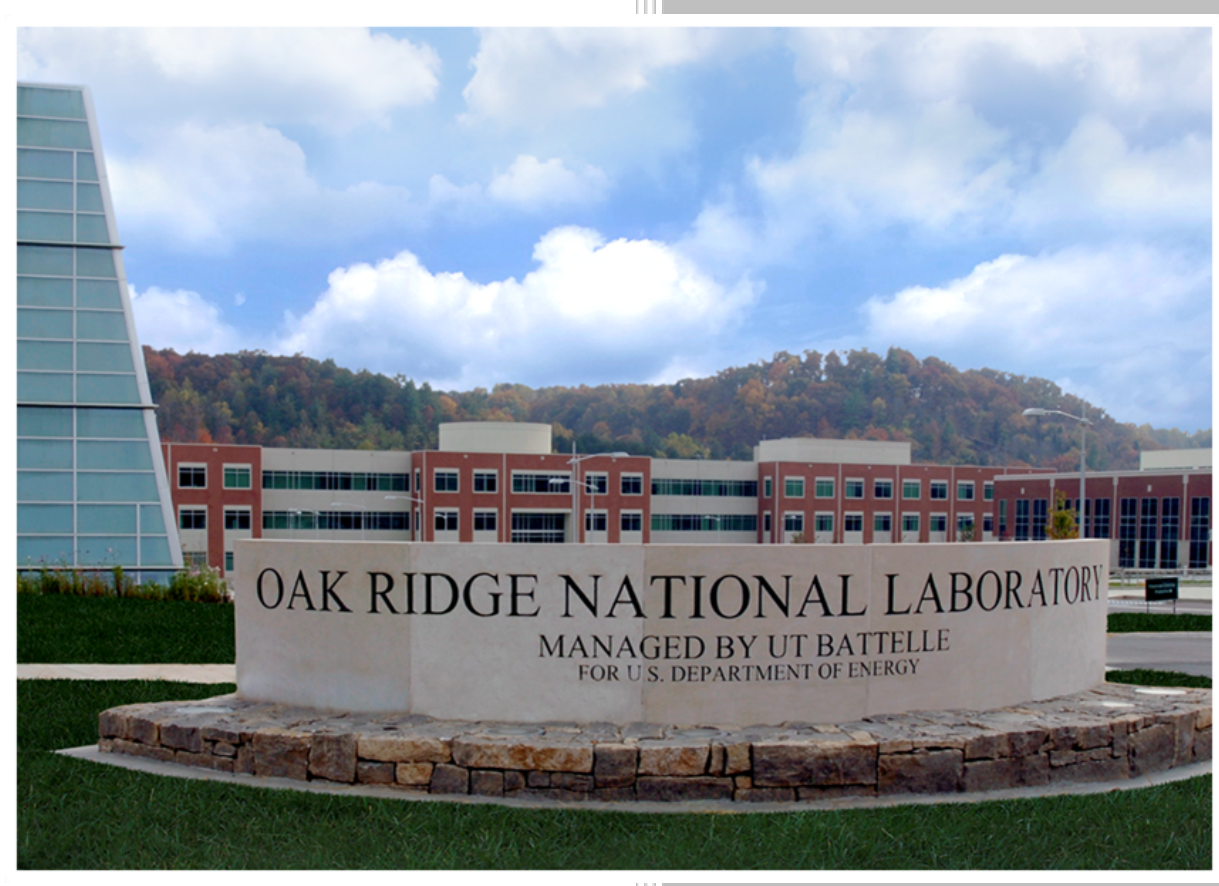

\section{Approved for public release. \\ Distribution is unlimited.}

Corson L. Cramer

Alicia M. Raftery

Andrew T. Nelson

September 2019 


\section{DOCUMENT AVAILABILITY}

Reports produced after January 1, 1996, are generally available free via US Department of Energy (DOE) SciTech Connect.

Website www.osti.gov

Reports produced before January 1, 1996, may be purchased by members of the public from the following source:

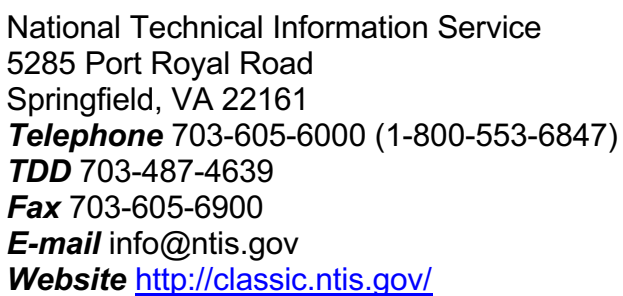

Reports are available to DOE employees, DOE contractors, Energy Technology Data Exchange representatives, and International Nuclear Information System representatives from the following source:

Office of Scientific and Technical Information

PO Box 62

Oak Ridge, TN 37831

Telephone 865-576-8401

Fax 865-576-5728

E-mail reports@osti.gov

Website http://www.osti.gov/contact.html

This report was prepared as an account of work sponsored by an agency of the United States Government. Neither the United States Government nor any agency thereof, nor any of their employees, makes any warranty, express or implied, or assumes any legal liability or responsibility for the accuracy, completeness, or usefulness of any information, apparatus, product, or process disclosed, or represents that its use would not infringe privately owned rights. Reference herein to any specific commercial product, process, or service by trade name, trademark, manufacturer, or otherwise, does not necessarily constitute or imply its endorsement, recommendation, or favoring by the United States Government or any agency thereof. The views and opinions of authors expressed herein do not necessarily state or reflect those of the United States Government or any agency thereof. 


\section{LITHOGRAPHY-BASED CERAMICS MANUFACTURING TECHNOLOGIES}

Corson L. Cramer

Alicia M. Raftery

Andrew T. Nelson

Date Published:

September 2019

Milestone M3CT-19OR06090132

Prepared by

OAK RIDGE NATIONAL LABORATORY

Oak Ridge, TN 37831-6283

managed by

UT-BATTELLE, LLC

for the

US DEPARTMENT OF ENERGY

under contract DE-AC05-00OR22725 



\section{CONTENTS}

CONTENTS

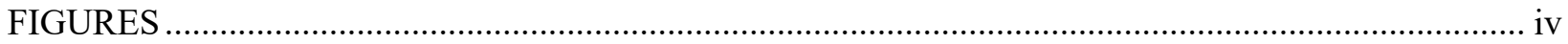

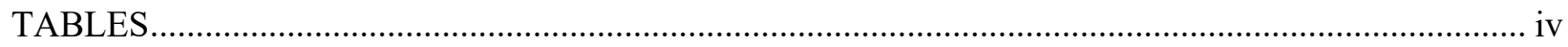

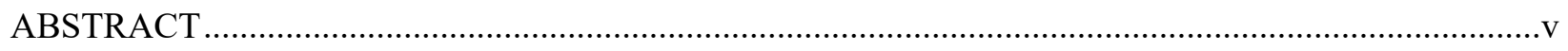

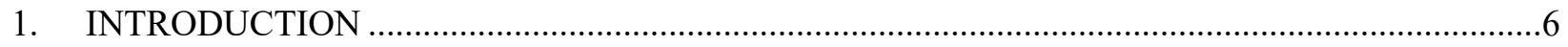

2. ORNL POWDER PREPARATION FOR CERAMIC LITHOGRAPHY PRINTING .......................6

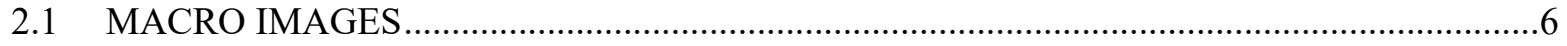

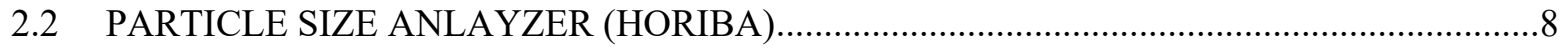

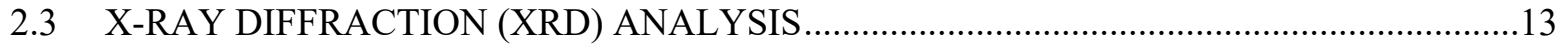

2.4 SCANNING ELECTRON MICROSCOPY (SEM) ANALYSIS .........................................15

2.5 BRUNAUER-EMMETT-TELLER (BET) SURFACE AREA AND REAL DENSITY ..........16

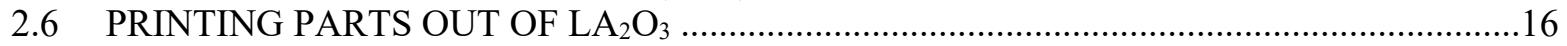

3. ORNL POWDER PREPARATION FOR CERAMIC LITHOGRAPHY PRINTING …...................17

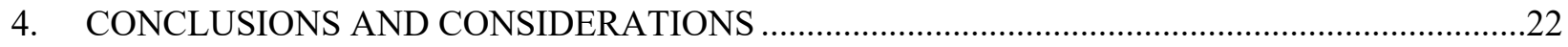

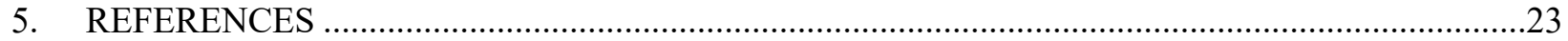




\section{FIGURES}

Figure 1. Photographs of cerium dioxide powder under different lighting conditions...............................

Figure 2. Photographs of lanthanum dioxide powder under different lighting conditions..........................8

Figure 3. Particle size distribution of as-received cerium dioxide powder used in this study.....................9

Figure 4. Particle size distribution of as-received lanthanum dioxide powder used in this study..............10

Figure 5. Particle size distribution of cerium dioxide powder used in this study following highenergy ball milling.

Figure 6. Particle size distribution of lanthanum dioxide powder used in this study following high energy ball milling.

Figure 7. X-ray diffraction pattern of cerium dioxide powder used in this study.....

Figure 8. X-ray diffraction pattern of lanthanum dioxide powder used in this study.

Figure 9. Scanning electron microscope images of (a) cerium dioxide powder and (b) lanthanum

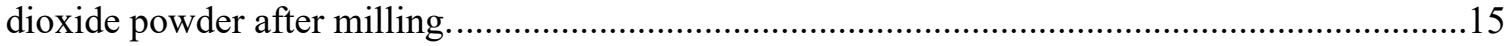

Figure 10. Photographs of lanthanum dioxide green bodies printed using lithography methods...............16

Figure 11. Photographs of alumina green bodies printed using lithography methods...............................17

Figure 12. Photographs of alumina printed using lithography following sintering ..................................18

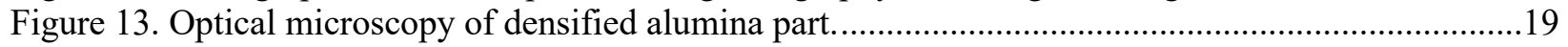

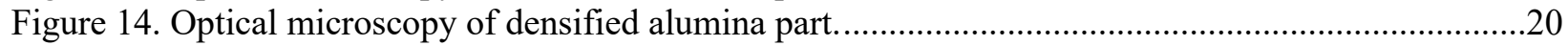

Figure 15. High magnification optical microscopy of densified alumina part. ........................................21

\section{TABLES}

Table 1. Surface Area and Density of Powders Used in This Study

Table 2. Comparison of Density and Porosity as Determined Using the Archimedes Method at Various Locations along Alumina Part 


\begin{abstract}
In this work, surrogate powders were prepared with lithography-based ceramic printing. Lanthanum oxide, a powder from Oak Ridge National Laboratory (ORNL), was prepared by milling, characterizing, and printing of coupon samples. The printing resulted in net-shaped green parts. Alumina, a more developed powder, was also printed and characterized at ORNL, and these parts were surrogate geometries larger than coupons that were sintered to net shape within $0.3 \%$ of the desired geometry.
\end{abstract}




\section{INTRODUCTION}

Surrogate powders have been sought to demonstrate the use of a resin-based, laser-cured 3D photolithography printing system. Photolithography is one additive manufacturing technology that is considered well suited to ceramic materials [1]. One of the most important objectives in this effort is to limit the light absorption from the laser source to the powder; therefore, the color of the powder is very important. White is ideal, and black will absorb too much. Some gray-colored powders have been printed successfully. Another possibility that has not yet been tried is the use of colored powers. An additional factor affecting this work is that the laser can penetrate through the slurry, which consists of photoresin and powder. This is possible because the powder is uniformly mixed, but it does not create a closed network of powder. Other ceramic powders of interest may be orange or brown before sintering, so two materials of similar color are chosen for development of ceramic lithography printing. In a parallel effort, alumina parts similar to those planned for the Transformational Challenge Reactor (TCR) are being printed to demonstrate the capabilities of this technology.

\section{ORNL POWDER PREPARATION FOR CERAMIC LITHOGRAPHY PRINTING}

In this research, two orangish-brown powders were selected, developed, characterized, and printed to mimic a process that can be used with other oxide materials. Two surrogate oxide ceramic powders were considered for color testing:

1. Cerium oxide from Moly Corp.

2. Lanthanum oxide from Moly Corp.

The powders were characterized for color with macro images. Particle size analysis was performed to verify the size of the powder. X-ray diffraction (XRD) was performed to verify the phase of the materials. Scanning electron microscopy (SEM) was performed to show the morphology and change of the powder. All properties can affect the printing, so it is important to track the powder, printing, and sintering to obtain the best surrogate simulations of the process.

\subsection{MACRO IMAGES}

Below are images of cerium oxide in different lighting. It is somewhat of an orange-brown color. This powder is somewhat clumpy and does not flow well, which is indicative of moisture absorption or smaller particulate clusters as particles. 


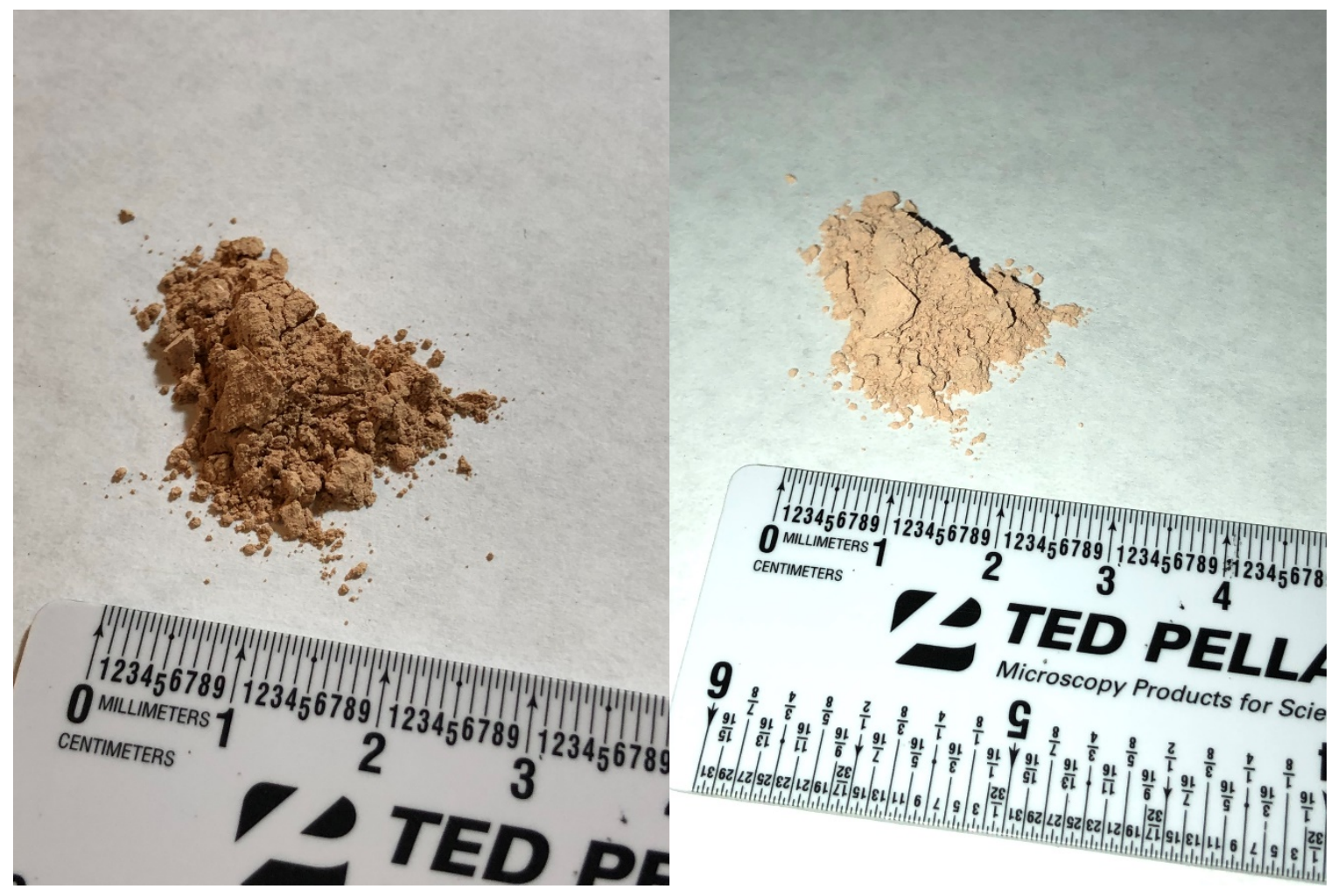

Figure 1. Photographs of cerium dioxide powder under different lighting conditions.

Below are images of lanthanum oxide from Moly Corp. It is also somewhat of an orange-brown color but not as deep as the cerium oxide color. This powder seems to spread and flow better than the cerium oxide powder. 


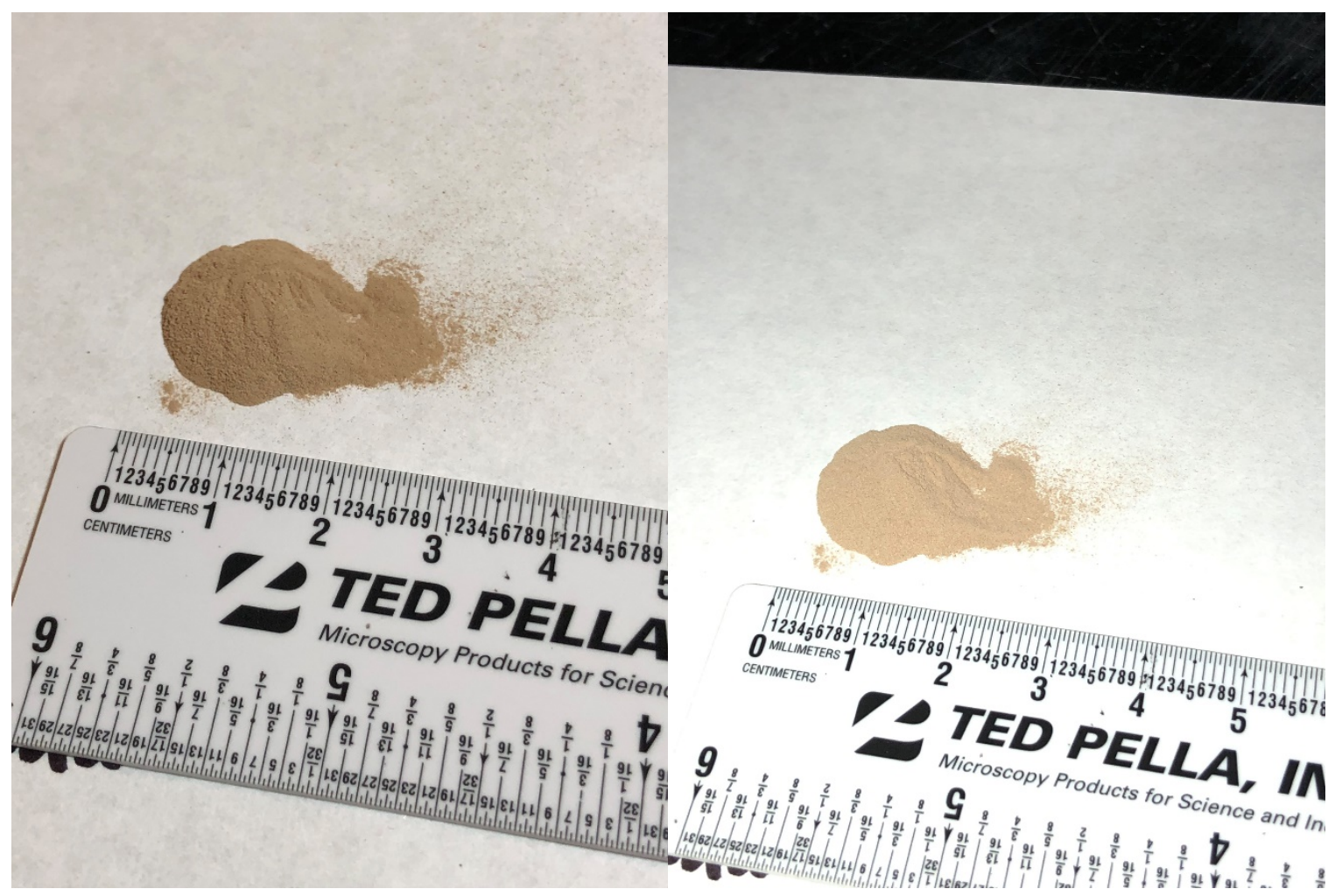

Figure 2. Photographs of lanthanum dioxide powder under different lighting conditions.

\subsection{PARTICLE SIZE ANLAYZER (HORIBA)}

The particle size distribution of the raw powders was measured with a Horiba LA-950 particle analyzer using laser scattering of aqueous powder aliquots with a volume distribution and particle percentage. The size distribution for the cerium oxide is shown below, indicating an average size of around 30 microns. The distribution is wide, and there might be some fines with lower particle sizes of $900 \mathrm{~nm}$. 


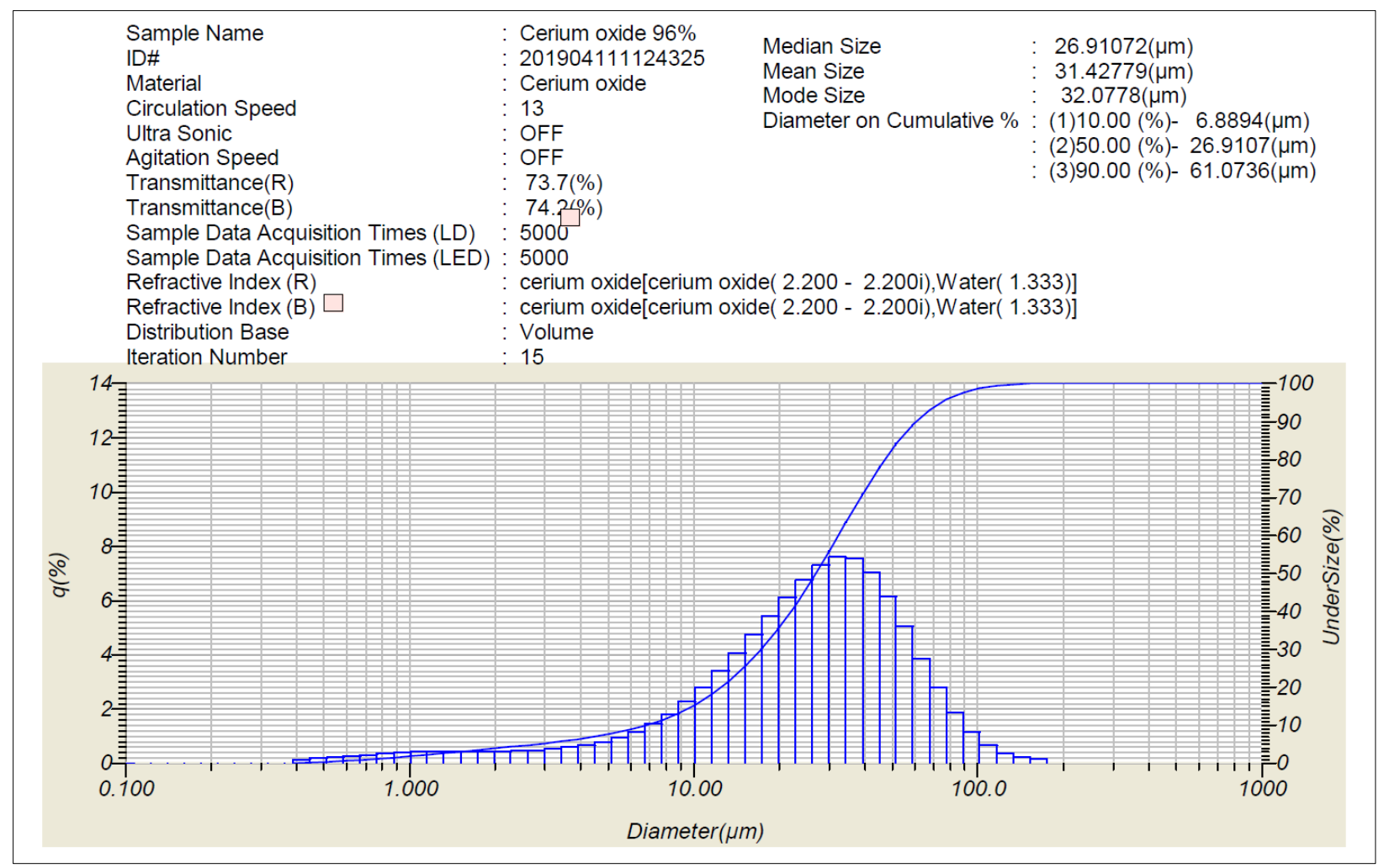

Figure 3. Particle size distribution of as-received cerium dioxide powder used in this study. 
The size distribution for the lanthanum oxide is shown below, indicating a mean particle size of around 40 microns. The size distribution is much narrower than that of the cerium oxide.

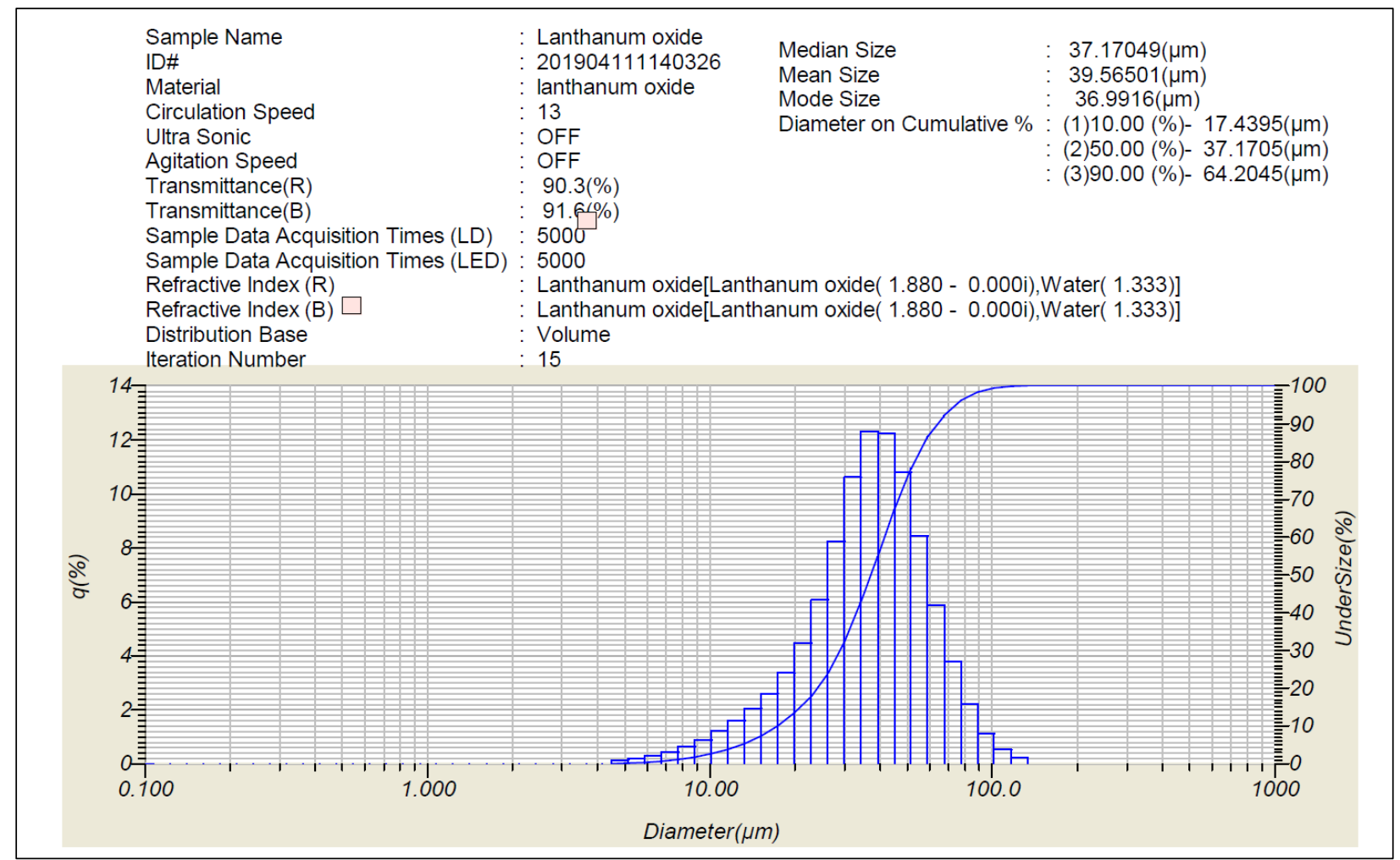

Figure 4. Particle size distribution of as-received lanthanum dioxide powder used in this study.

These powder sizes were deemed to be too large for adequate slurry development, ceramic lithography printing, or sintering, so both powders were ball milled for 4 hours with zirconia media in alcohol on a rolling mill system and then dried, sieved, and analyzed again for powder size. Once the powder size was adequate, the remainder of the powder characterization process was performed. 
Below is the particle size analysis for the milled ceria powder. The new average particle size is slightly below 5 microns, so this powder is better suited for ceramic lithography printing compared to the 30 micron average particle size before milling.

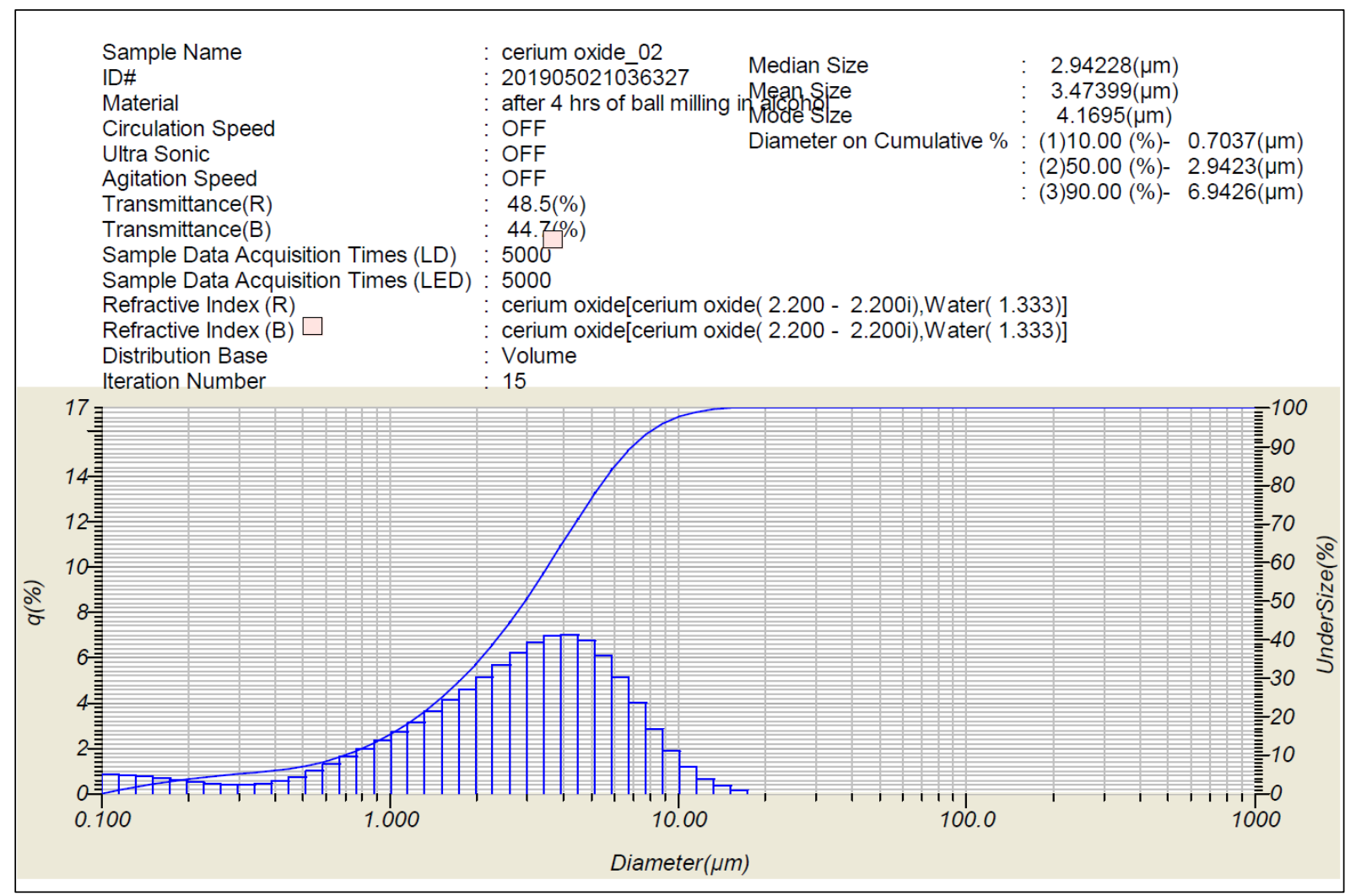

Figure 5. Particle size distribution of cerium dioxide powder used in this study following high-energy ball milling. 
Below is the particle size analysis for the milled lanthanum oxide powder. The new average particle size is also slightly below 5 microns, so this powder is also better suited for ceramic lithography printing compared to the 40 micron average particle size before milling.

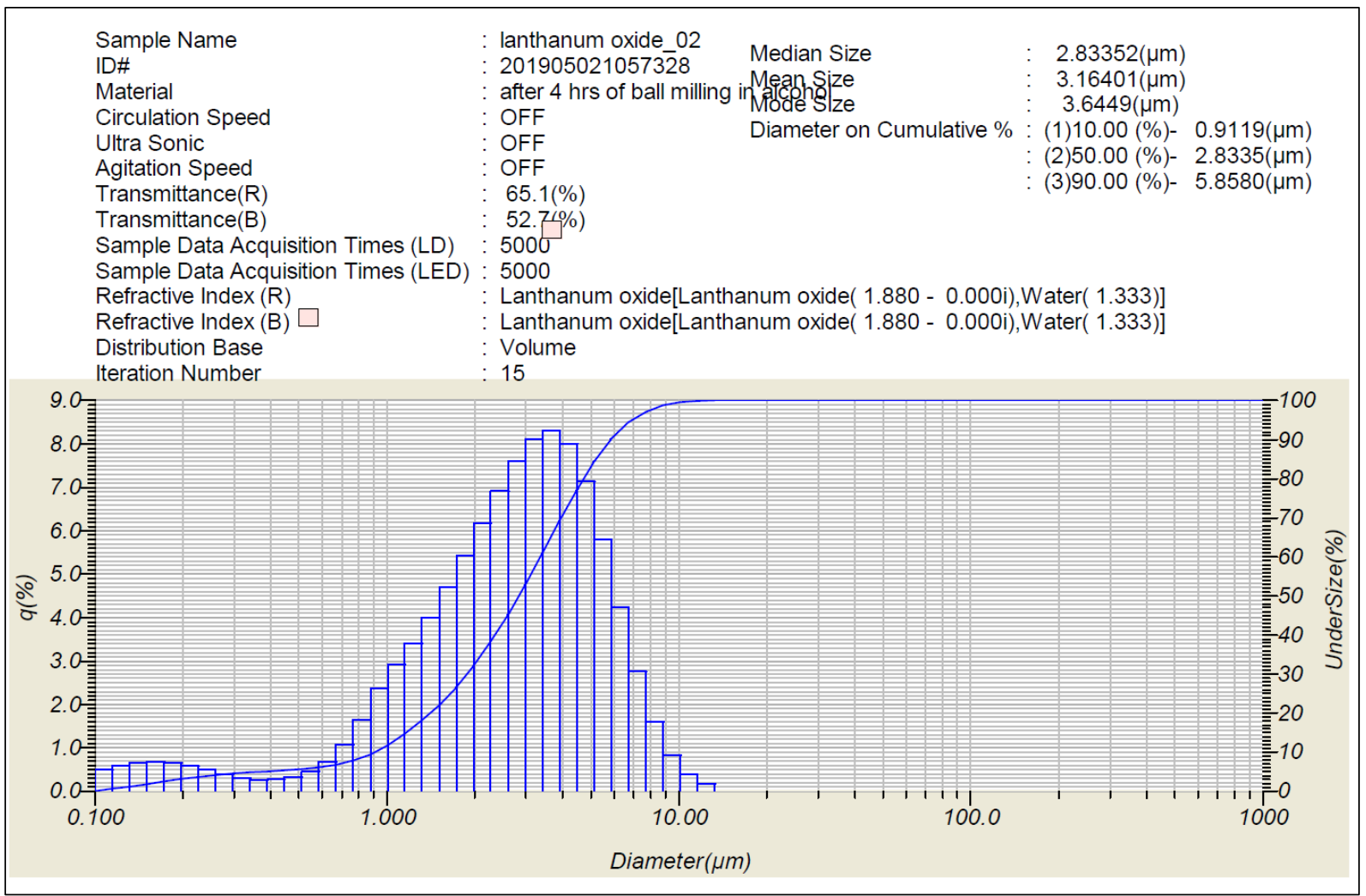

Figure 6. Particle size distribution of lanthanum dioxide powder used in this study following high energy ball milling. 


\subsection{X-RAY DIFFRACTION (XRD) ANALYSIS}

Continuous $\theta-2 \theta$ scans were performed on the Panalytical X'pert diffractometer from nominally $5-90^{\circ} 2 \theta$ using $\mathrm{CuK} \alpha$ radiation $(\lambda=1.540598 \AA)$. All scans used $14^{\circ}$ fixed slits, $12^{\circ}$ anti-scatter slit, 0.04 Soller slits coupled with a $10 \mathrm{~mm}$ mask (beam length). For the phase identification procedure, a search match was conducted using the Jade software and the International Centre for Diffraction Data (ICDD) database. The ceria XRD patterns obtained from the sample cerium oxide $96 \% 5310$ are presented below, and the pattern is identified with the $\mathrm{CeO}_{2}$ phase.

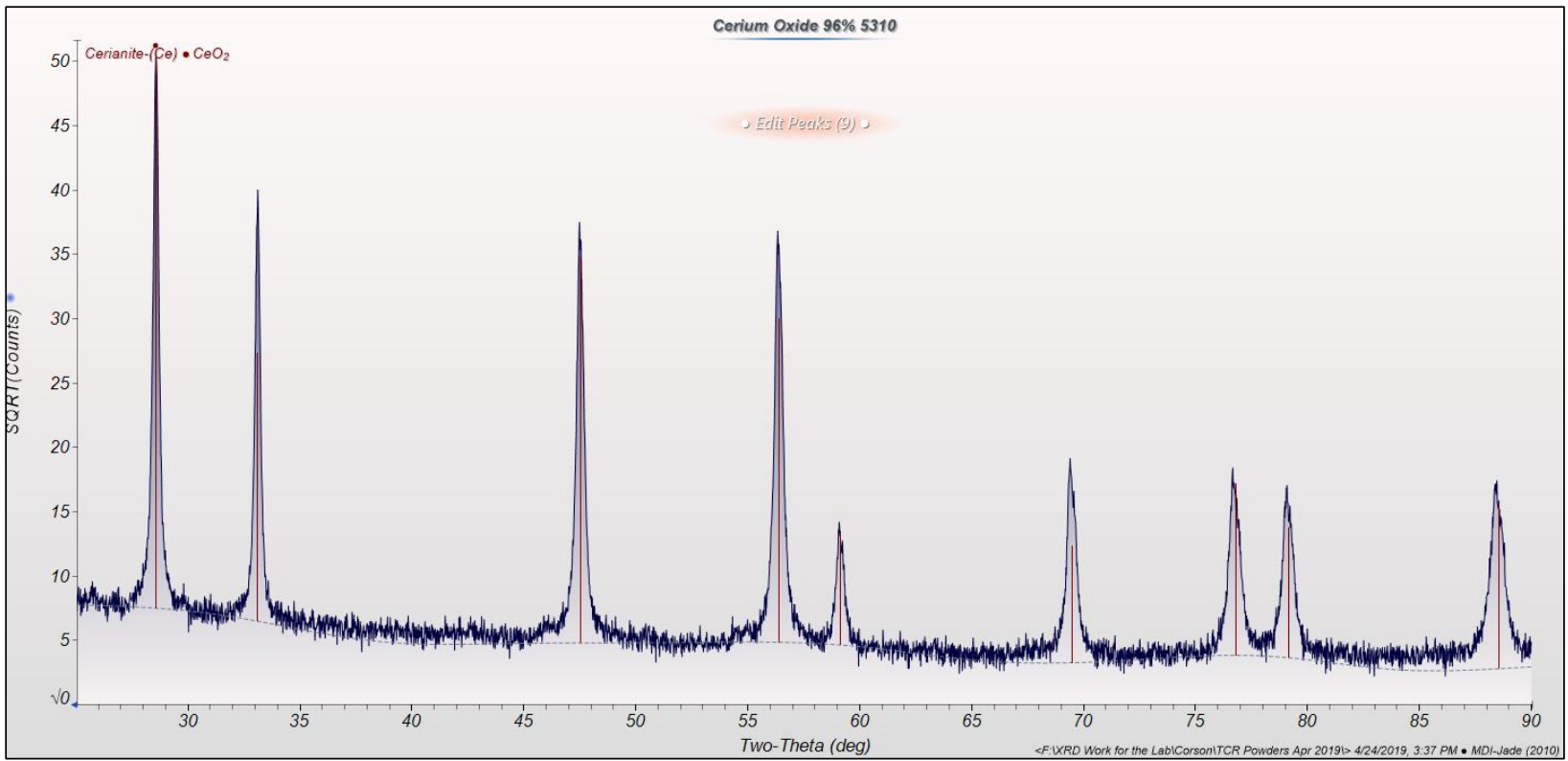

Figure 7. X-ray diffraction pattern of cerium dioxide powder used in this study. 
The lanthanum oxide XRD patterns obtained from the sample lanthanum oxide from Moly Corp 5232 are presented below. The $\mathrm{La}_{2}\left(\mathrm{CO}_{3}\right) \mathrm{O}_{2}, \mathrm{La}(\mathrm{OH})_{3}$, $\mathrm{Ce}$ and $\mathrm{Ce}\left(\mathrm{CO}_{3}\right) \mathrm{OH}$ peaks are identified, and there is one peak that remains unidentified.

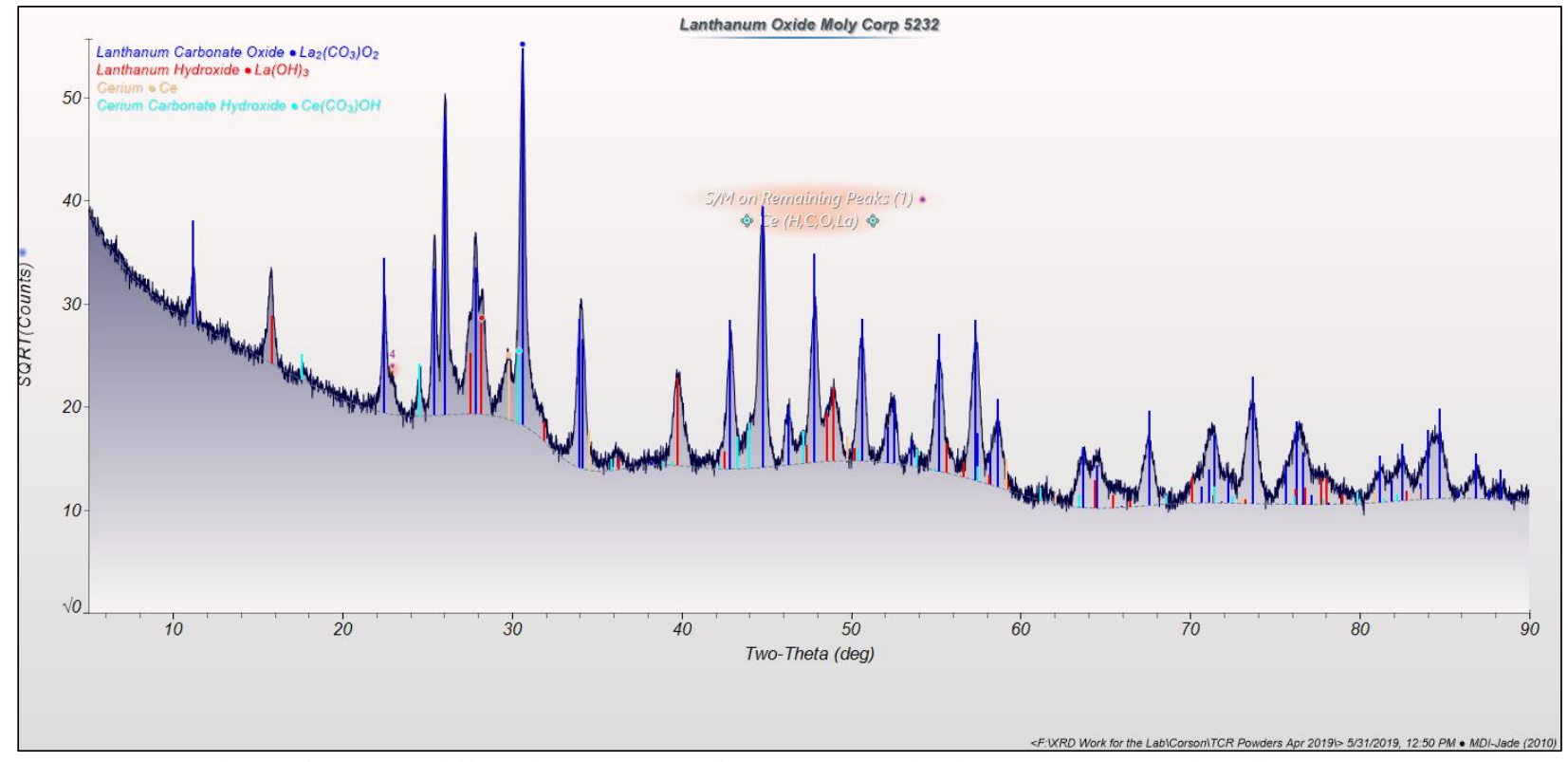

Figure 8. X-ray diffraction pattern of lanthanum dioxide powder used in this study. 


\subsection{SCANNING ELECTRON MICROSCOPY (SEM) ANALYSIS}

SEM images of the two powers were also analyzed, as shown in Figure 9 below, with ceria on the left and lanthanum oxide on the right. The distribution of the ceria powder is much wider than that of the lanthanum oxide. For resin mixing and sintering, the narrower the size distribution, the more uniformly these materials behave. Bimodal powder blends show good results, but they are underdeveloped for ceramic lithography printing, so the lanthanum oxide powder is more attractive for printing compared to the ceria powder.
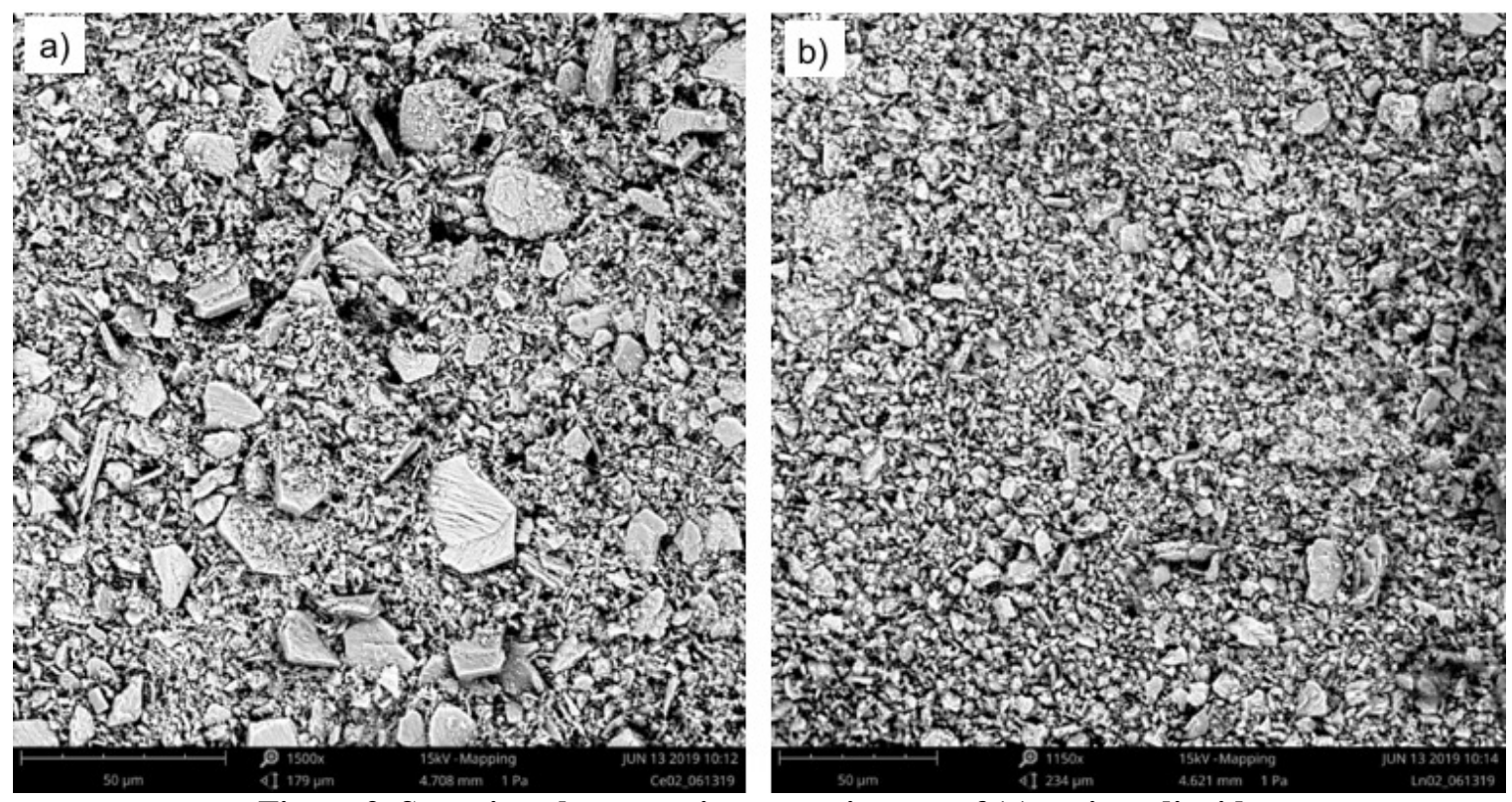

Figure 9. Scanning electron microscope images of (a) cerium dioxide powder and (b) lanthanum dioxide powder after milling. 


\subsection{BRUNAUER-EMMETT-TELLER (BET) SURFACE AREA AND REAL DENSITY}

The final two important properties to consider for the ceramic lithography printing are the surface area of the particles and the real density of the powder. These properties affect resin wetting, as well as distribution of the powder into the resin. Below are results for the two powders. Lanthanum oxide has more favorable properties for printing.

Table 1. Surface Area and Density of Powders Used in This Study

\begin{tabular}{lcc}
\hline Powder & $\begin{array}{c}\text { BET surface } \\
\text { area }\left(\mathbf{m}^{2} / \mathbf{g}\right)\end{array}$ & $\begin{array}{c}\text { Real density } \\
\text { pycnometer } \\
(\mathbf{g} / \mathbf{c c})\end{array}$ \\
\hline Ceria & 5.22 & 7.22 \\
Lanthanum oxide & 8.62 & 5.07 \\
\hline
\end{tabular}

\subsection{PRINTING PARTS OUT OF $\mathrm{LA}_{2} \mathrm{O}_{3}$}

The lanthanum oxide powder was chosen for printing because of its powder size, distribution, and surface area. Details from the lithography printing are not available currently because of intellectual property protection, but the prints were successful with adequate laser penetration depth. Printed parts are shown below and had enough strength to be transported from France to the United States. No further work was performed with these prints, but this effort served as a good demonstration and proof that an orangecolored powder can be printed with this method. The color did not negatively affect the laser path and scattering, so the resin can be cured around this powder when the laser is directed into the slurry during the printing of $2 \mathrm{D}$ layers.
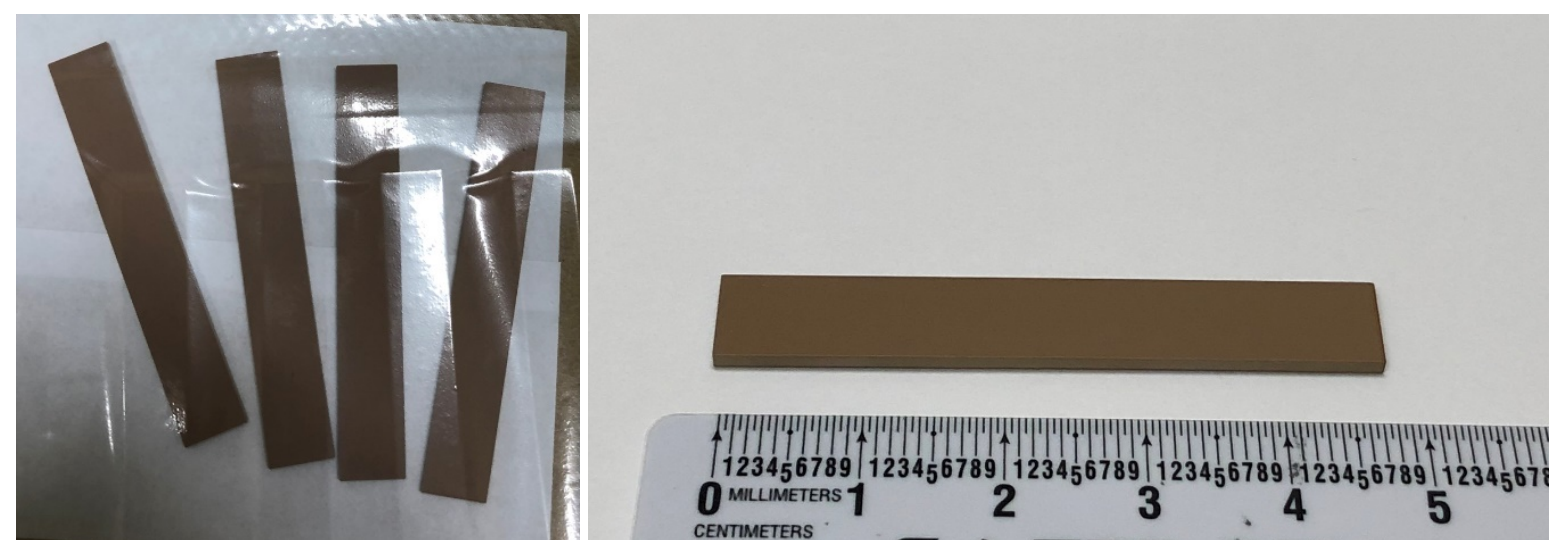

Figure 10. Photographs of lanthanum dioxide green bodies printed using lithography methods. 


\section{ORNL POWDER PREPARATION FOR CERAMIC LITHOGRAPHY PRINTING}

3D Ceram has developed the ceramic lithography printing process to a high level with alumina powders, so the geometries of actual TCR parts were printed with alumina, debinded, and sintered to show the capability of this technology. Details of their alumina powders and processing are not currently available due to intellectual propriety restrictions. Nonetheless, alumina parts were printed, or they were printed, debinded, and sintered in France and sent to ORNL.

Below is a solid alumina print of a y-shaped part printed on its side. This part is green, still containing cured binder resin, so it demonstrates the printing capability. It is anticipated that a part of this thickness will most likely crack upon debinding, so further studies beyond scanning were not conducted. There is a maximum thickness that can be reached to ensure binder burnout without cracking, so all parts that go through the debind process need to have a wall thickness below the threshold to ensure binder burnout without cracking.
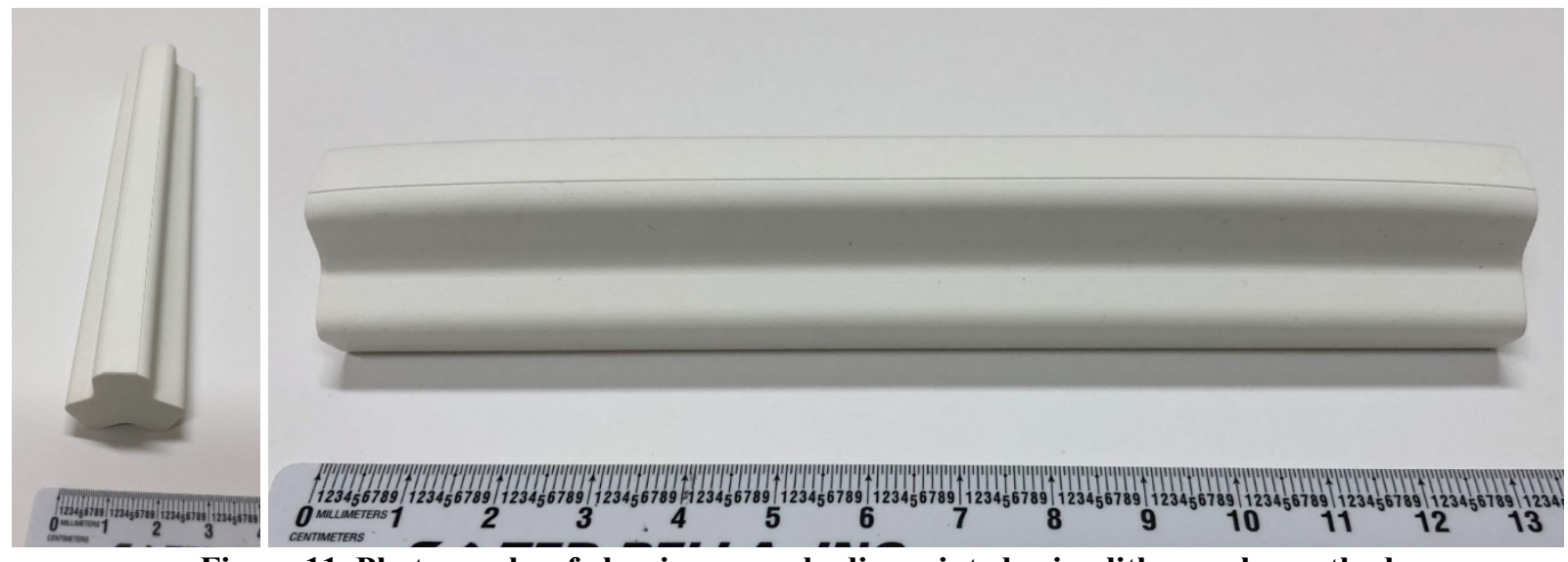

Figure 11. Photographs of alumina green bodies printed using lithography methods. 
A fully densified part with ceramic lithography printing was also created, but the original geometry required slight modification to accommodate the debinding process. The green part was solid, but to survive the debind process without cracking, channels were created throughout the geometry to ensure that the wall thickness was below a certain length. The fully densified part with channels is shown below.

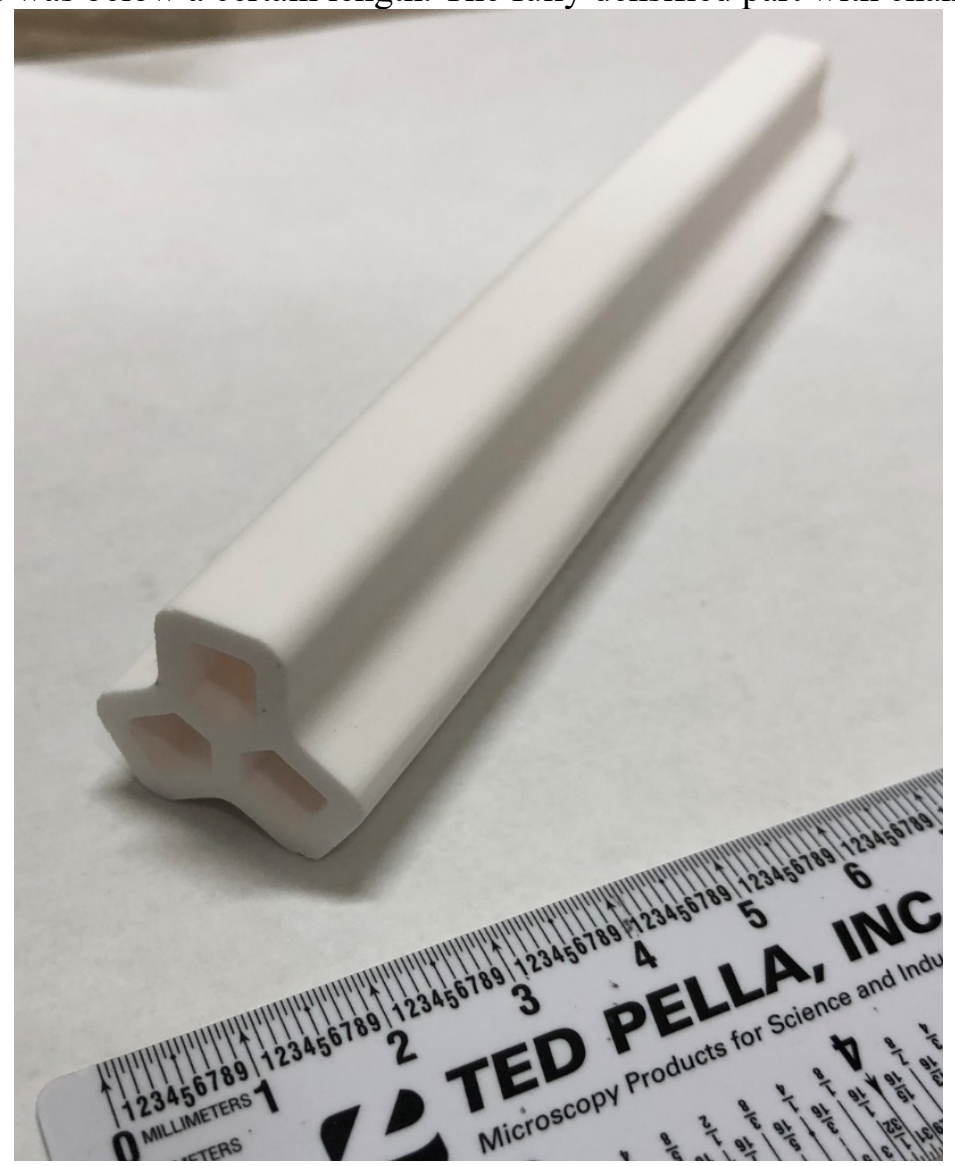

Figure 12. Photographs of alumina printed using lithography following sintering. 
Three sections of one of the parts were sliced out of the part, mounted, and polished for microstructural characterization. The cross sections showed a highly dense material with no cracks. Some pores were visible, but this was expected for in powder-based ceramics.

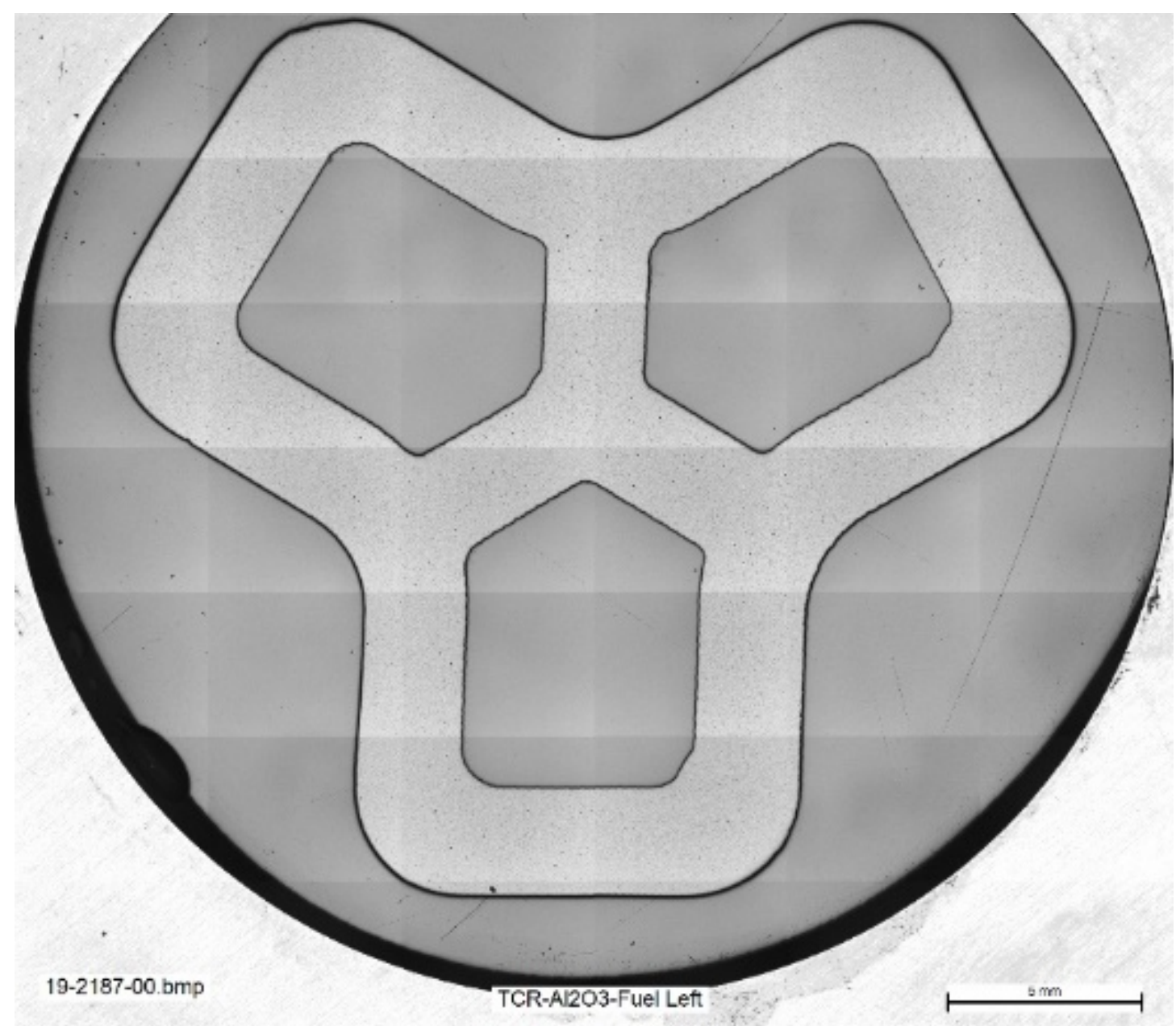

Figure 13. Optical microscopy of densified alumina part. 


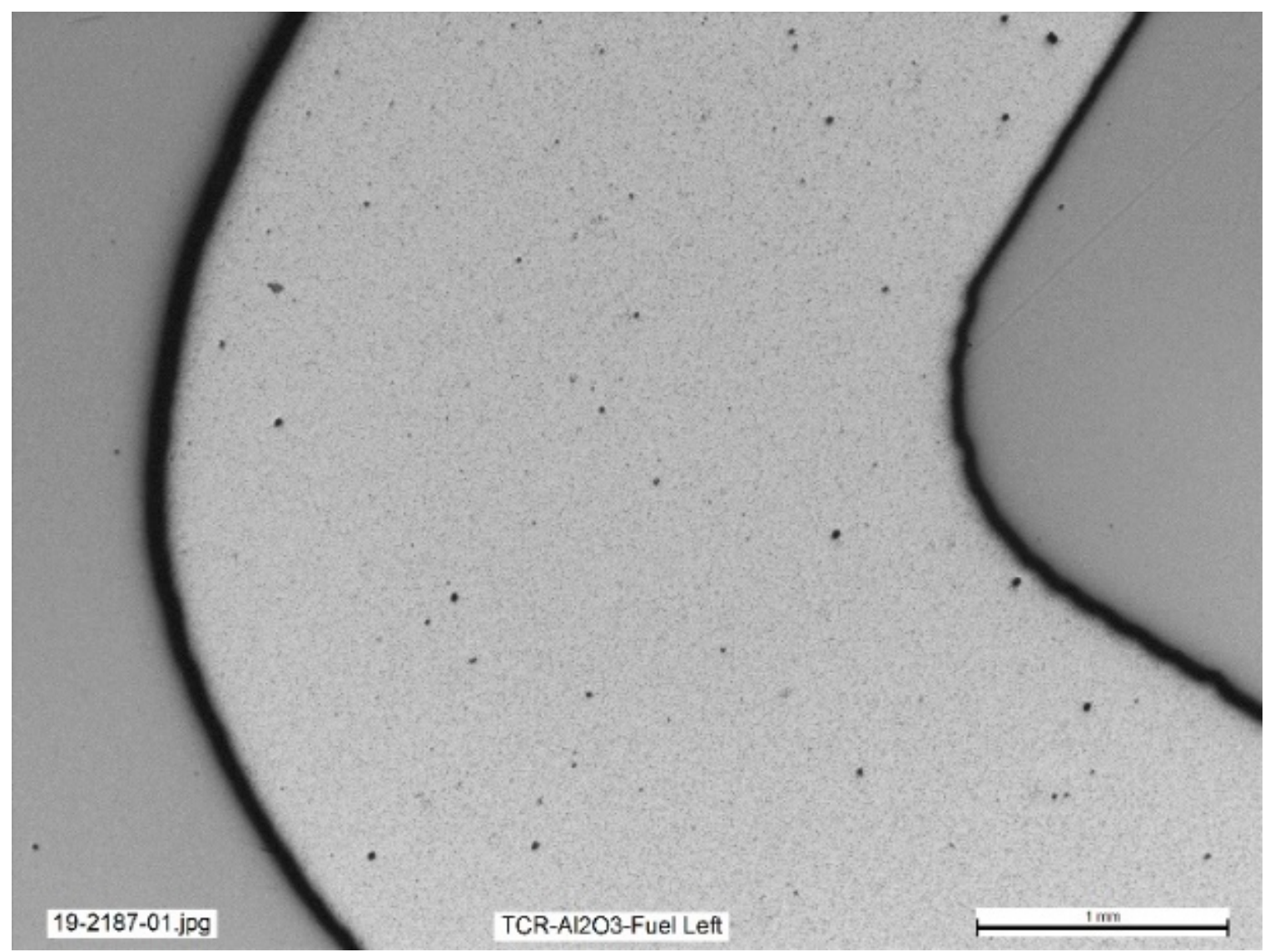

Figure 14. Optical microscopy of densified alumina part.

A closer look at the microstructure shows that the pores are in the 5-10-micron size range. Also, a grainy structure of differently oriented alumina grains is visible. 


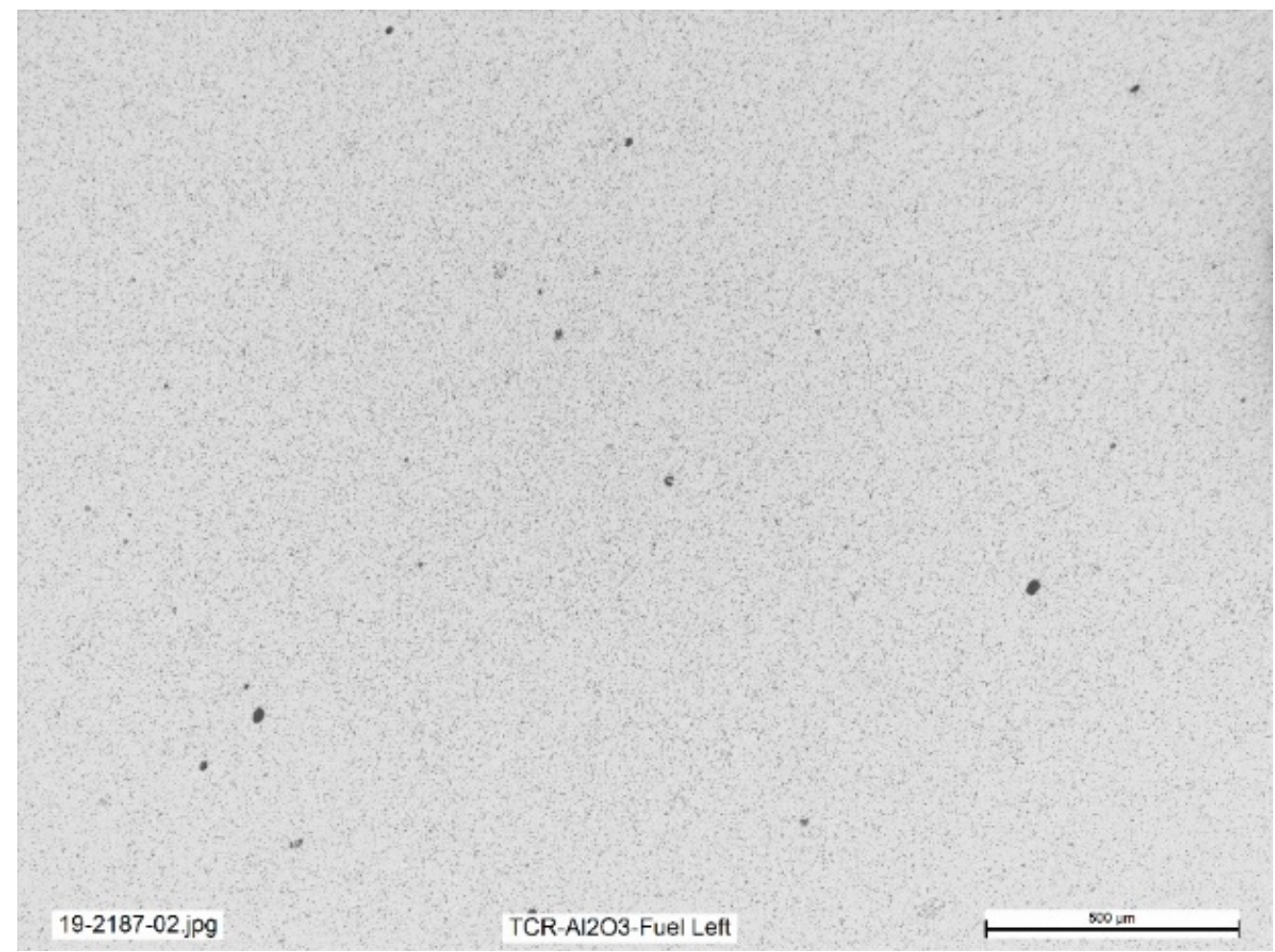

Figure 15. High magnification optical microscopy of densified alumina part.

A final check of the density was made by performing Archimedes density measurements. Since these parts are quite complex, geometric density was difficult to accurately achieve, so three more sections were cut out of the sample, and the Archimedes densities were measured for all three parts. The results showed very low open porosity, so the powder structure has mostly closed all pore channel pathways. Also, the relative densities were in the $95-96 \%$ range, which is very high.

Table 2. Comparison of Density and Porosity as Determined Using the Archimedes Method at Various Locations along Alumina Part

\begin{tabular}{lccccc}
\hline $\begin{array}{l}\text { Sample } \\
\text { description }\end{array}$ & $\begin{array}{c}\text { Theoretical } \\
\text { density }\left(\mathbf{g} / \mathbf{c m}^{\mathbf{3}}\right)\end{array}$ & $\begin{array}{c}\text { Closed } \\
\text { density }\left(\mathbf{g} / \mathbf{c m}^{\mathbf{3}}\right)\end{array}$ & $\begin{array}{c}\text { Bulk } \\
\text { density }\left(\mathbf{g} / \mathbf{c m}^{\mathbf{3}}\right)\end{array}$ & $\begin{array}{c}\text { Percent } \\
\text { theoretical } \\
\text { density (\%) }\end{array}$ & $\begin{array}{c}\text { Open } \\
\text { porosity (\%) }\end{array}$ \\
\hline Left & 3.95 & 3.85 & 3.80 & $\mathbf{9 6 . 1 2}$ & $\mathbf{1 . 4 4}$ \\
Middle & 3.95 & 3.80 & 3.76 & $\mathbf{9 5 . 1 4}$ & $\mathbf{1 . 1 3}$ \\
Right & 3.95 & 3.83 & 3.81 & $\mathbf{9 6 . 4 7}$ & $\mathbf{0 . 5 5}$ \\
\hline
\end{tabular}




\section{CONCLUSIONS AND CONSIDERATIONS}

Ceramic lithography printing is a promising way to achieve highly dense oxide ceramic parts in complex and near-net shapes. Typical white oxide ceramics like ceria, zirconia, and alumina can easily be used with the photoresin and laser. The technology was advanced further to try orange-colored powder, and the prints were successful. The most developed material - alumina — was used to test the geometry capabilities of this method, and it was highly successful with one caveat: thick samples would not hold up during the debind. There are research paths forward with this technology. With purchase of a 3D Ceram machine, further development can be done with other surrogate materials. Some of the planned research areas include measuring the penetration depth of different colored powder, increasing the debinding thickness, and scaling up to larger parts, which may result in warping and distortion. 


\section{REFERENCES}

1. Z. Chen, Z. Li, J. Li, C. Liu, C. Lao, Y. Fu, C. Liu, Y. Li, and Y. He. "3D Printing of Ceramics: A Review." Journal of the European Ceramic Society 39 (2019) 661-687. 